\title{
Granitik Agregaların Alkali Silis Reaksiyonu Yönünden Değerlendirilmesi
}

\author{
Evaluation of Alkali-Silica Reactivity of Granitic Aggregates
}

Nuray MANNASOĞLU, Murat YILMAZ, Atiye TUĞRUL

İstanbul Üniversitesi, Mühendislik Fakültesi, Jeoloji Mühendisliği Bölümü, Avcılar, ISTANBUL

$\begin{array}{lll}\text { Geliş (received) } & : & \text { 02 Mart (March) } 2016 \\ \text { Düzeltme (revised) } & : & \text { 23 Mart (March) } 2016 \\ \text { Kabul (accepted) } & : & \text { 24 Mart (March) } 2016\end{array}$

ÖZ

Agrega, beton bileşiminde en çok kullanılan malzeme olduğundan, özellikleri betonun dayanıklılığını (durabilitesini) doğrudan etkilemektedir. Agreganın türü, mineralojisi, dokusu gibi jeolojik faktörler betonun dayanımında ve dayanıklılığında önemli etkilere sahiptir. Bu araştırmada; Türkiye'nin farklı bölgelerinden alınan granitik kayaçlar, betonda alkali silis reaksiyonu açısından incelenmiştir. Çalışma kapsamında; öncelikle granitik kayaçların mineralojik, petrografik ve kimyasal özellikleri incelenmiş, daha sonra bu granit örnekler üzerinde hızlandırılmış harç çubuğu deneyleri yapılmıştır. Oluşan alkali silis reaksiyonunun etkileri taramalı elektron mikroskobu (SEM) ile incelenmiştir. Elde edilen veriler, granitlerin beton agregası olarak kullanılması durumunda, örneklerin büyük çoğunluğunun alkali silis reaksiyonu açısından riskli olmadığını göstermektedir.

Anahtar Kelimeler: Agrega, Alkali-Silis Reaksiyonu, Granit, Türkiye.

\section{ABSTRACT}

Aggregate has widely used in concrete composition and its properties directly affects the durability of concrete. Geological factors such as aggregate type, mineralogy and texture have significant effects on concrete strength and durability. In this study, granitic rocks collected from different parts of Turkey, have been investigated from the point of alkali-silica reactions in concrete. Firstly, mineralogical, petrographic and chemical characteristics of granitic rocks were investigated. Then, accelerated mortar bar tests were performed on these granite samples. The effects of alkali-silica reactions were also investigated by scanning electron microscope (SEM). According to results obtained, granites, when used as concrete aggregate, are not generally found to be potentially dangerous for alkali-silica reactions.

Key Words: Aggregate, Alkali-Silica Reaction, Granite, Turkey.

M. Yılmaz

E-posta: yilmazm@istanbul.edu.tr 
Mannasoğlu, Yılmaz, Tuğrul

\section{GíRIŞ}

Alkali-silis reaksiyonu (ASR); reaktif silis formları içeren agregaların çimento ve/veya dış kaynaklardan gelen alkali oksitlerle reaksiyona girmesi ve bunun sonucunda genleşebilme özelliğine sahip bir jelin meydana gelmesidir (Neville, 1981; Moranville-Regourd, 1997). Bu jel, su emdikçe hacmi daha çok artmakta, betonda çatlamalara neden olmakta (Nixon ve Page, 1987; Binal, 2008) ve bu çatlaklar betonun dayanımını önemli oranda düşürmektedir (Fookes, 1980; Struble ve Diamond, 1981; Wakizaka, 1998; Marzouk ve Langdon, 2003).

Reaksiyonun oluşabilmesi için, çimentodaki alkali içeriğinin, bir başka deyişle $\mathrm{Na}_{2} \mathrm{O}+0.658$ $\mathrm{K}_{2} \mathrm{O}$ değerinin, \% 0.60'1 ve ortamdaki nemin 20 ${ }^{\circ} \mathrm{C}$ sicaklıkta \% 85'i aşması gerekir (Arnould, 1997). Bu koşullardan herhangi biri olmazsa alkali-silis reaksiyonu nedeniyle bir genleşme de olmayacaktır. Bunun dişında ortamın gözenekliliği de reaksiyon açısından önemlidir (Swamy, 1992; Moranville-Regourd, 1997; Rivard vd., 2002).

Bazı agregalar kökenleri ile ilgili olarak reaksiyona girebilen silisten oluşan bileşenleri içerebilirler. $\mathrm{Bu}$ tür bileşenler, betonun boşluk suyunda çözünen alkali hidroksit ile güçlü bir kimyasal reaksiyona girer ve önce berrak, çoğunlukla yüksek konsantrasyonlu ve sonra yüksek viskoziteli alkali silis çözeltisini meydana getirir (Ben Haha, 2006). Agreganın alkaliye duyarlı bileşenleri böylece yumuşar ve çözünür (Swamy, 1992). Reaksiyon süresi ve şiddeti, özellikle agreganın alkaliye duyarlı bileşenlerinin cins ve miktarına, tane büyüklüğüne ve dağılışına, betonun boşluğunda bulunan çözeltideki alkali hidroksit miktarına ve sertleşmiş betonun çevre koşullarına bağlıdır
(Hobbs ve Gutteridge, 1979; Stark vd., 1993; Gillott ve Rogers, 1994; Prince vd., 2001). Bu nedenle, alkaliye duyarlı tanelerin tek başına değerlendirilmesi yeterli değildir (Fookes, 1980; Swamy, 1992; Fournier ve Berube, 2000).

Agregayı oluşturan bileşenlerin tümü ve formu agreganın reaktifliğini belirler. Alkali-silis reaksiyonu ilk kez Stanton (1940) tarafından tanımlanmıştır. Reaksiyona neden olan mineraller; opal (McConnell vd., 1950; Ineson, 1990; Bell, 1998), kalsedon ve volkan camı (Rhoades, 1942; McConnell vd., 1950; Katayama ve Kaneshige, 1986; Ineson, 1990; Shrimer vd., 2000), kriptokristalin kuvars (Stanton, 1940), tridimit (Hornibrook vd., 1943; McConnell vd., 1950; Ineson, 1990; Bell, 1998), kristobalit (Landgren ve Sweet, 1952; Mielenz, 1954; Ineson, 1990) ile basınç etkisinde kalmış çatlaklı kuvarstır (McConnell vd., 1950; Gogte, 1973; Bell, 1998). Genel olarak opal, çört ve kalsedon gibi aktif silisçe zengin kayaçların alkali-silis reaksiyonuna neden olmalarının yanı sıra, silisçe zengin kayaçların çoğu da bu reaksiyona neden olabilmektedir; (1) granit ve kuvarsit (Mullick vd., 1986); (2) fillit, kuvarsit ve gnays (Buck, 1986); (3) granodiyorit (Moranville-Regourd, 1997); (4) sedimanter agregalar (Shayan ve Lancucki, 1986); (5) çört ve silttaşı (Joyce, 1996). Bu tür malzemeler, beton üretiminde kullanıldıklarında reaksiyon oluşturabilir. Alkali-silis reaksiyonu konusunda yapılan araştırmalarda, fillitler içerisinde bulunan hidromikanın (illit) alkali-silikat reaksiyonuna neden olduğu ifade edilmiştir (McConnell vd., 1950; Bell, 1998; Lorenzi vd., 2001). Alkaliagrega reaksiyonunun belirlenmesi amaciyla birçok standart geliştirilmiştir. Bunlardan baz1lar1; BS 7943 (1999), BS 812: Part 123 
(1999), TS 2517 (1977), ASTM C 289 (1994), ASTM C 295 (1994), ASTM C-1260 (1994) ve CSA A23.2 (1994)'tür.

$\mathrm{Bu}$ araştırma kapsamında, Türkiye'nin değişik bölgelerinden alınan farklı doku ve bileşime sahip granitik kayaçların, betonda alkali silis reaksiyonu açısından incelenmesi amaçlanmıştır. Araştırmanın yapıldığı inceleme alanlar1; Marmara Bölgesi'ndeyeralan KırklareliBalaban (KB), Çatalca-Şeytandere (CS), Gebze-Sancaktepe (GS), Armutlu-F1stıklı (AF), Kapıdağ Yarımadası'nda bulunan Erdek (ER), Çanakkale-Kestanbol (CK), Ege Bölgesi'nde yer alan Bergama-Kozak (IB), Karadeniz Bölgesi'nde yer alan Giresun-Bulancak (GV),
İç Anadolu Bölgesi'ndeki Aksaray-Yaylak Köyü (AY) ve Aksaray-Sipahi Köyü (AS) bölgelerini kapsamaktadır (Şekil 1). Bu çalışmada öncelikle, granitik kayaçların bileşiminde alkalisilis reaksiyonuna yol açabilen minerallerin varlığ1, polarizan mikroskop incelemeleriyle belirlenmiştir. Daha sonra, kimyasal analizlerle bu kayaçların içerdiği ana element oksit yüzdeleri belirlenmiştir. ASTM C 1260 (1999) tarafindan verilen esaslara uyularak hızlandırılmış harç çubuğu deneyleri ile granitik kayaçların alkalisilis reaktivitesi araştırılmıştır. SEM (Taramalı Elektron Mikroskobu) incelemeleri ile reaksiyon ürünlerinin gelişimi ve agrega-çimento sınırı incelenmiştir.

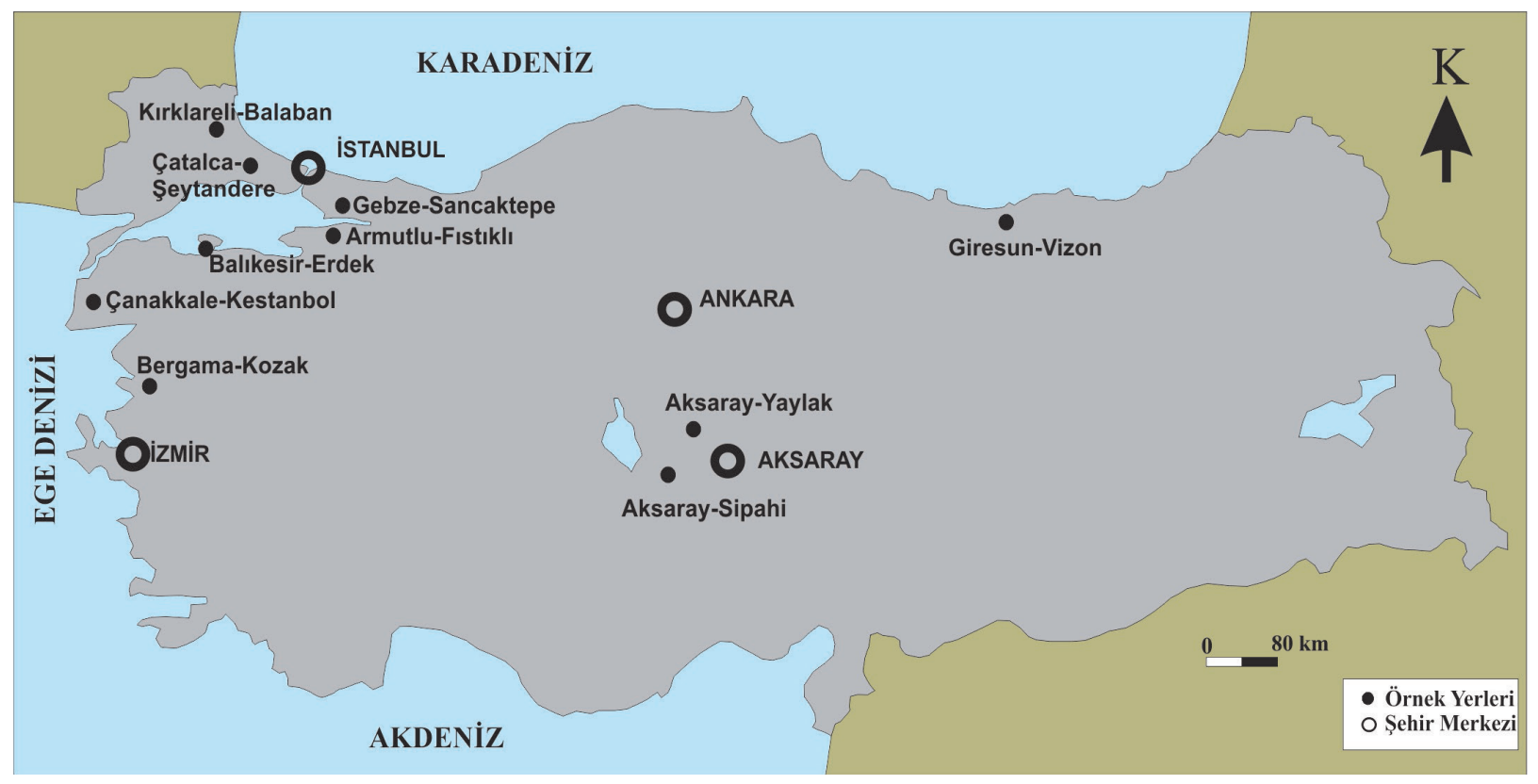

Sekil 1. Çalışamada kullanılan granitik kayaçların alındığı ocak yerlerinin yer bulduru haritası.

Figure 1. Map showing the sampling locations of the granitic rocks tested in the present work. 
Mannasoğlu, Yılmaz, Tuğrul

\section{INCELENEN GRANITIK KAYAÇLARIN MINERALOJIK VE PETROGRAFIKK ÖZELLİKLERİ}

Türkiye'nin çeşitli bölgelerinden alınan granitik kayaçların mineralojik ve petrografik özelliklerini belirlemek amacıyla ince kesitler hazırlanmıştır. Hazırlanan ince kesitler üzerinde yapilan incelemeler sonucunda belirlenen granitik kayaçların petrografik özellikleri Çizelge 1'de ve Şekil 2'de sunulmuştur.

Çizelge 1. Granitik kayaçların petrografik özellikleri.

Table 1. Petrographic properties of the granitic rocks.

\begin{tabular}{|c|c|c|c|c|c|c|}
\hline $\begin{array}{l}\text { Örnek } \\
\text { Kodu }\end{array}$ & Alındı̆̆ı yer & Doku & $\begin{array}{l}\text { Kristal boyutu } \\
\text { (Erkan, 2004) }\end{array}$ & Mineralojik bileşim & $\begin{array}{l}\text { Ayrışma/ } \\
\text { Hidrotermal } \\
\text { alterasyon }\end{array}$ & $\begin{array}{l}\text { Kayaç adı } \\
\text { (Streckeisen, 1979) }\end{array}$ \\
\hline GV & Giresun-Bulancak & $\begin{array}{l}\text { Holokristalin tanesel } \\
\text { doku }\end{array}$ & İnce-orta taneli & $\begin{array}{l}\text { Ortoklaz, plajiyoklaz, kuvars, } \\
\text { hornblend, biyotit, klorit, } \\
\text { epidot, titanit }\end{array}$ & $\begin{array}{l}\text { Albitleşme, } \\
\text { killeşme, } \\
\text { serizitleşme, } \\
\text { kloritleşme }\end{array}$ & Kuvars monzonit \\
\hline IB & Bergama-Kozak & $\begin{array}{l}\text { Tüm kristalli yarı } \\
\text { özşekilli tanesel doku }\end{array}$ & İnce-orta taneli & $\begin{array}{l}\text { Plajiyoklaz, kuvars, ortoklaz, } \\
\text { hornblend, biyotit, çok fazla } \\
\text { opak min. }\end{array}$ & $\begin{array}{l}\text { Killeşme, } \\
\text { serizitleşme }\end{array}$ & Kuvars monzonit \\
\hline $\mathrm{CK}$ & $\begin{array}{l}\text { Çanakkale- } \\
\text { Kestanbol }\end{array}$ & $\begin{array}{l}\text { Holokristalin tanesel } \\
\text { doku }\end{array}$ & Orta-iri taneli & $\begin{array}{l}\text { Ortoklaz, plajiyoklaz, kuvars } \\
\text { amfibol (hornblend), biyotit }\end{array}$ & $\begin{array}{l}\text { Kloritleşme, } \\
\text { epidotlaşma, } \\
\text { killeşme }\end{array}$ & Kuvars monzonit \\
\hline ER & Bandırma-Erdek & $\begin{array}{l}\text { Holokristalin tanesel } \\
\text { doku }\end{array}$ & İnce taneli & $\begin{array}{l}\text { Kuvars, plajiyoklaz, ortoklaz, } \\
\text { biyotit, amfibol (mafik } \\
\text { mineral oranı az), klorit, } \\
\text { muskovit }\end{array}$ & $\begin{array}{l}\text { Kloritleşme, } \\
\text { muskovitleşme, } \\
\text { killeşme, } \\
\text { serizitleşme } \\
\end{array}$ & $\begin{array}{l}\text { Granit/ } \\
\text { monzogranit }\end{array}$ \\
\hline $\mathrm{KB}$ & Kırklareli-Balaban & $\begin{array}{l}\text { Blastoholokris-talin } \\
\text { (blasto-granüler doku) }\end{array}$ & İnce-orta taneli & $\begin{array}{l}\text { Kuvars, feldispat (ortoklaz, } \\
\text { plajiyoklaz) amfibol, } \\
\text { muskovit, epidot, klorit, sfen }\end{array}$ & $\begin{array}{l}\text { Feldispatlarda } \\
\text { kloritleşme, } \\
\text { epidotlaşma, } \\
\text { albitleşme }\end{array}$ & $\begin{array}{l}\text { Granit/ } \\
\text { monzogranit } \\
\text { (Metagranit) }\end{array}$ \\
\hline AY & Aksaray-Yaylak & $\begin{array}{l}\text { Holokristalin tanesel } \\
\text { doku }\end{array}$ & Orta taneli & $\begin{array}{l}\text { Ortoklaz, plajiyoklaz, kuvars, } \\
\text { biyotit ve az miktarda } \\
\text { amfibol, opak min., zirkon }\end{array}$ & $\begin{array}{l}\text { Killeşme, } \\
\text { serizitleşme }\end{array}$ & $\begin{array}{l}\text { Granit/ } \\
\text { monzogranit }\end{array}$ \\
\hline $\mathrm{AF}$ & Armutlu-F1stıklı & $\begin{array}{l}\text { Holokristalin tanesel } \\
\text { doku }\end{array}$ & Orta-iri taneli & $\begin{array}{l}\text { Kuvars, plajiyoklaz, ortoklaz } \\
\text { biyotit, amfibol, piroksen }\end{array}$ & $\begin{array}{l}\text { Kloritleşme, } \\
\text { killeşme, } \\
\text { serisitleşme }\end{array}$ & $\begin{array}{l}\text { Granit/ } \\
\text { monzogranit }\end{array}$ \\
\hline GS & Gebze-Sancaktepe & $\begin{array}{l}\text { Holokristalin tanesel } \\
\text { doku }\end{array}$ & Orta-iri taneli & $\begin{array}{l}\text { Ortoklaz, kuvars, plajiyoklaz, } \\
\text { biyotit, zirkon }\end{array}$ & $\begin{array}{l}\text { Serizitleşme, } \\
\text { albitleşme, } \\
\text { pertitleşme }\end{array}$ & $\begin{array}{l}\text { Granit/ } \\
\text { monzogranit }\end{array}$ \\
\hline AS & Aksaray-Sipahi & $\begin{array}{l}\text { Holokristalin tanesel } \\
\text { doku }\end{array}$ & Orta-iri taneli & $\begin{array}{l}\text { Kuvars, plajiyoklaz, ortoklaz, } \\
\text { hornblend, biyotit, epidot, } \\
\text { klorit, titanit, zirkon }\end{array}$ & $\begin{array}{l}\text { Kloritleşme, } \\
\text { epidotlaşma }\end{array}$ & $\begin{array}{l}\text { Granit/ } \\
\text { Monzogranit } \\
\text { (Metagranit) }\end{array}$ \\
\hline $\mathrm{CS}$ & Çatalca-Şeytandere & $\begin{array}{l}\text { Holokristalin tanesel } \\
\text { doku }\end{array}$ & İnce-orta taneli & $\begin{array}{l}\text { Ortoklaz, kuvars, plajiyoklaz, } \\
\text { amfibol, biyotitten muskovit, } \\
\text { klorit }\end{array}$ & $\begin{array}{l}\text { Serizitleşme, } \\
\text { albitleşme, } \\
\text { killeşme }\end{array}$ & $\begin{array}{l}\text { Granit/ } \\
\text { monzogranit }\end{array}$ \\
\hline
\end{tabular}




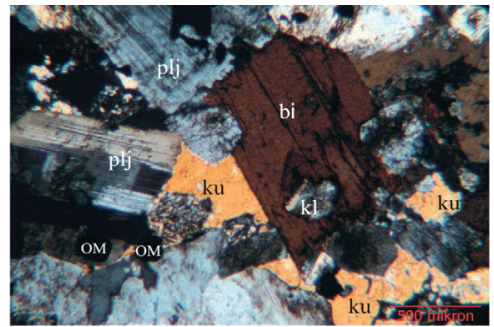

(a)

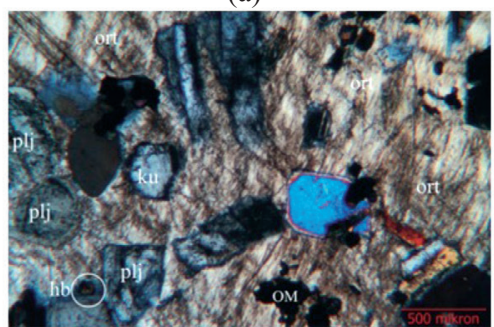

(c)

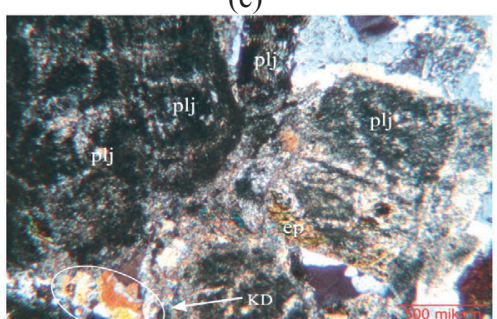

(e)

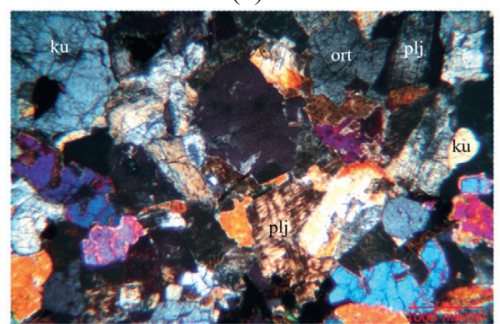

(g)

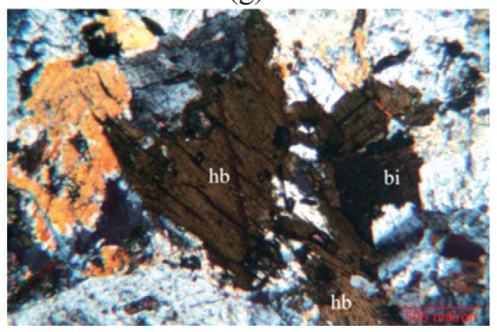

(1)

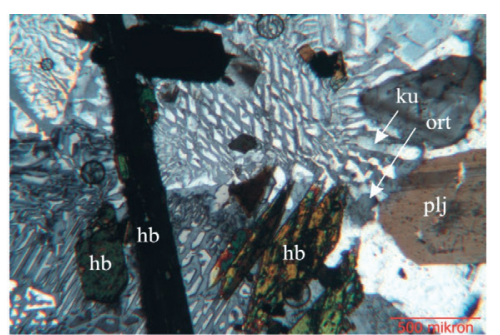

(b)

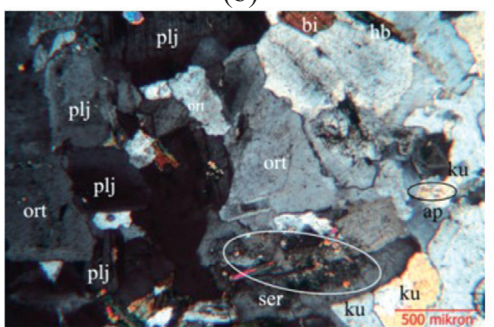

(d)

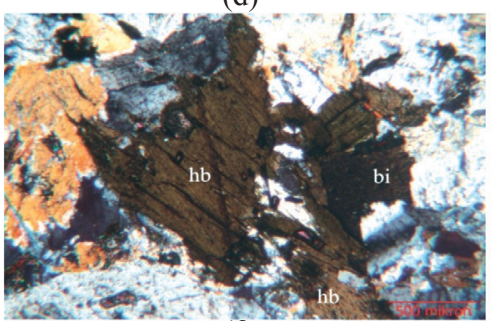

(f)

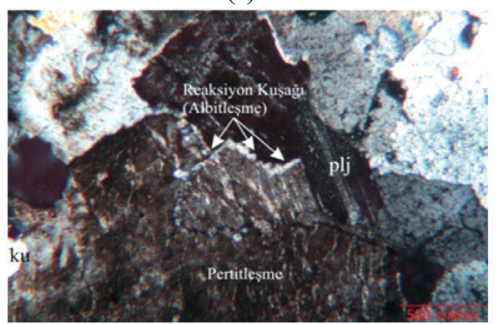

(h)

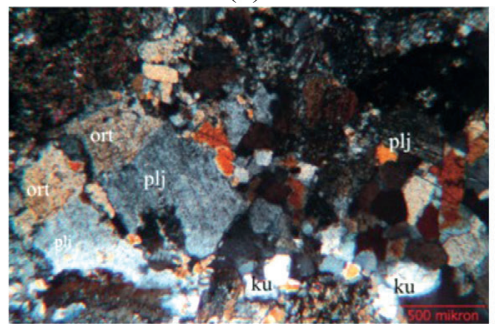

(i)

Şekil 2. Granitik kayaçların ince kesit görünümleri, (a) GV, (b) IB, (c) CK, (d) ER, (e) KB, (f) AY, (g) AF, (h) GS, (1) AS, (i) CS. (ort: ortoklaz, plj: plajiyoklaz, ku: kuvars, bi: biyotit, kl: klorit, OM: opak mineral, hb: hornblend, ser: serizit, ap: apatit, ep: epidot, KD: kataklastik doku).

Figure 2. Thin sections of the granitic rocks, (a) GV, (b) IB, (c) CK, (d) ER, (e) KB, (f) AY, (g) AF, (h) GS, (l) AS, (i) CS. (ort: orthoclase, plj: plagioclase, ku: quartz, bi: biotite, kl: chlorite, OM: opaque mineral, hb: hornblende, ser: serizite, ap: apatite, ep: epidote, KD: cataclastice texture). 
Mannasoğlu, Yılmaz, Tuğrul

Granitik kayaç örnekleri üzerinde nokta bu oranlardan türetilmiş olan QAP (Streckeisen, sayacı ile yapılan petrografik incelemelerden elde edilen modal mineral oranları Çizelge 2'de, 1967) Diyagramı Şekil 3’te sunulmuştur.

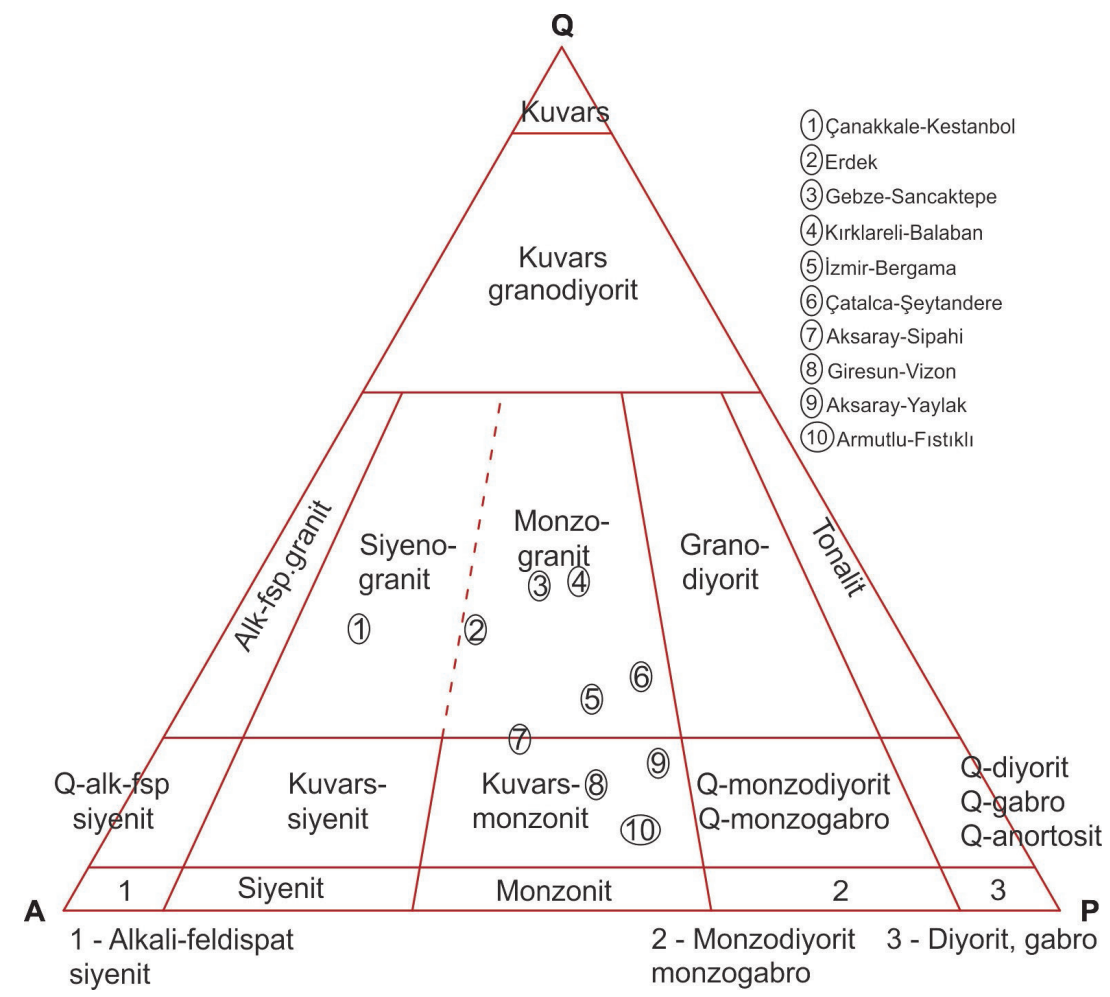

Şekil 3. Granitlerin modal minerolojik bileşimine göre Q (Kuvars)- A (Alkali Feldspat)- P (Plajiyoklaz) diyagramında (Streckeisen, 1967) siniflandırılmasi.

Figure 3. Modal mineralogic composition of granites according to Q(Quartz)-A (Alkali Feldspar)-P(Plagioclase) classification (Streckeisen, 1967).

Çizelge 2. Granitik kayaçların modal mineral analiz sonuçları.

Table 2. Results of modal mineral analyses of the granitic rocks.

\begin{tabular}{lcccccccc}
\hline Örnek kodu & Kuvars & Plajiyoklaz & Ortoklaz & Biyotit & Hornblend & Altere min. & Klorit & Opak min. \\
\hline GV & 7.6 & 39 & 34.6 & 5.4 & 4.6 & 5.3 & 1.9 & 1 \\
\hline IB & 14.7 & 43.9 & 26.8 & 8.5 & 5.2 & 0.5 & - & - \\
\hline CK & 12.1 & 37.4 & 37.5 & 4.7 & 7.5 & 0.7 & - & - \\
\hline ER & 24 & 40.5 & 26 & 5.2 & 1.8 & 2.5 & - & - \\
\hline KB & 21.5 & 16.4 & 28.2 & 1.2 & 5.5 & 26.9 & - & - \\
\hline AY & 14.3 & 25 & 31.6 & 9.3 & 1 & 16.2 & - & 2.5 \\
\hline AF & 29.3 & 24.8 & 21.9 & 13.1 & 3 & 6.6 & 1.2 & - \\
\hline GS & 18.9 & 8.3 & 31.1 & 2.9 & - & 36.7 & 0.5 & 1.4 \\
\hline AS & 19.5 & 33.4 & 28.5 & 5.2 & 4.5 & 2.7 & 2.3 & 1.5 \\
\hline CS & 27.2 & 20.1 & 24.4 & 7.1 & 4.4 & 15.6 & 1.1 & - \\
\hline
\end{tabular}




\section{INCELENEN GRANITIK KAYAÇLARIN KIMMYASAL ÖZELLİKLERİ}

Araştırma kapsamındaki granitik kayaçların kimyasal özelliklerini belirlemek amaciyla kimyasal analizler yapılmıştır. Analizler için, granitik kayaç örneklerinden taze örnekler hazırlanmış ve içerdikleri ana element oksit yüzdeleri belirlenmiştir. Analizler, Kanada ACME Laboratuvarında XRF yöntemine göre yapılmıştır. Elde edilen sonuçlar Çizelge 3'te sunulmuştur.
Çizelge 4. Deneylerde kullanılan çimentonun (CEM I 42.5 R) özellikleri.

Tablo 4. Properties of cement used in the experiments.

\begin{tabular}{lc}
\hline Kimyasal özellikler & Deney sonuçları (\%) \\
\hline Kızdırma kaybı & 4.03 \\
\hline $\mathrm{SiO}_{2}$ & 19.61 \\
\hline $\mathrm{Al}_{2} \mathrm{O}_{3}$ & 4.84 \\
\hline $\mathrm{Fe}_{2} \mathrm{O}_{3}$ & 3.13 \\
\hline $\mathrm{CaO}$ & 62.81 \\
\hline $\mathrm{MgO}$ & 1.30 \\
\hline $\mathrm{SO}_{3}$ & 3.09 \\
\hline $\mathrm{K}_{2} \mathrm{O}$ & 0.74 \\
\hline $\mathrm{Na}_{2} \mathrm{O}$ & 0.22 \\
\hline Çözünmeyen kalıntı & 0.21
\end{tabular}

Çizelge 3. Granitik kayaçların ana element oksit yüzdeleri.

Table 3. Main element oxide percentages of the granitic rocks.

\begin{tabular}{ccccccccccc}
\hline \multirow{2}{*}{ Örnek kodu Ana element oksit yüzdeleri (\%) } \\
\cline { 2 - 12 } & $\mathrm{SiO}_{2}$ & $\mathrm{Al}_{2} \mathrm{O}_{3}$ & $\mathrm{Fe}_{2} \mathrm{O}_{3}$ & $\mathrm{MgO}$ & $\mathrm{CaO}$ & $\mathrm{Na}_{2} \mathrm{O}$ & $\mathrm{K}_{2} \mathrm{O}$ & $\mathrm{TiO}_{2}$ & $\mathrm{P}_{2} \mathrm{O}_{5}$ & $\mathrm{MnO}$ \\
\hline $\mathrm{GV}$ & 60.94 & 16.49 & 5.92 & 1.10 & 3.75 & 3.09 & 6.39 & 0.45 & 0.37 & 0.17 \\
\hline $\mathrm{IB}$ & 65.29 & 14.36 & 4.46 & 2.34 & 5.03 & 3.29 & 2.93 & 0.37 & 0.47 & 0.10 \\
\hline $\mathrm{CK}$ & 63.53 & 14.84 & 4.87 & 2.21 & 4.52 & 3.82 & 4.06 & 0.61 & 0.35 & 0.10 \\
\hline ER & 71.63 & 14.39 & 2.01 & 0.50 & 2.90 & 3.84 & 3.15 & 0.25 & 0.16 & 0.08 \\
\hline $\mathrm{KB}$ & 69.45 & 12.80 & 3.49 & 1.66 & 3.50 & 2.88 & 3.26 & 0.63 & 0.34 & 0.09 \\
\hline AY & 71.79 & 14.52 & 2.32 & 0.35 & 2.58 & 3.28 & 4.14 & 0.13 & 0.08 & 0.07 \\
\hline AF & 67.77 & 15.45 & 3.08 & 0.78 & 2.54 & 3.84 & 3.22 & 0.32 & 0.09 & 0.15 \\
\hline $\mathrm{GS}$ & 73.10 & 13.54 & 1.96 & 0.24 & 0.77 & 3.48 & 5.15 & 0.44 & 0.06 & 0.03 \\
\hline AS & 68.76 & 15.30 & 2.49 & 0.70 & 3.94 & 4.41 & 2.51 & 0.36 & 0.27 & 0.08 \\
\hline CS & 74.38 & 12.72 & 3.15 & 0.41 & 0.82 & 3.43 & 3.40 & 0.25 & 0.06 & 0.10 \\
\hline
\end{tabular}

\section{ALKALİ SILISS REAKSIYYONU}

\section{Hızlandırılmış Harç Çubuğu Deneyi}

İncelenen granit örneklerindeki aktif silis ile diğer reaktif minerallerin zararlı etkilerini belirlemek amaciyla, ASTM C1260 (1999) tarafindan verilen esaslara uyularak hızlandırılmış harç çubuğu deneyleri yapılmıştır. $\mathrm{Bu}$ deneylerle, incelenen granitlerin, çimento hamuruyla oluşturabileceği reaksiyon nedeniyle meydana gelen genleşmelere bağlı boyca uzamaları belirlenmiştir. Deneylerde kullanılan çimentonun (CEM I 42.5R portland çimentosu) özellikleri Çizelge 4'te sunulmuştur.
Deneyler, en az üç örnek üzerinde yapılmış olup, elde edilen genleşme oranları; 7, 14, 16, 21 ve 28 günlük dönemler halinde Çizelge 5 'te ve Şekil 4'te sunulmuştur. Bu çizelgede görüldüğü gibi, tüm ölçümler sonucunda, ortalama en yüksek genleşmenin AS kodlu granit ile üretilen harç çubuklarında olduğu belirlenmiştir (Şekil 4). 
Mannasoğlu, Yılmaz, Tuğrul

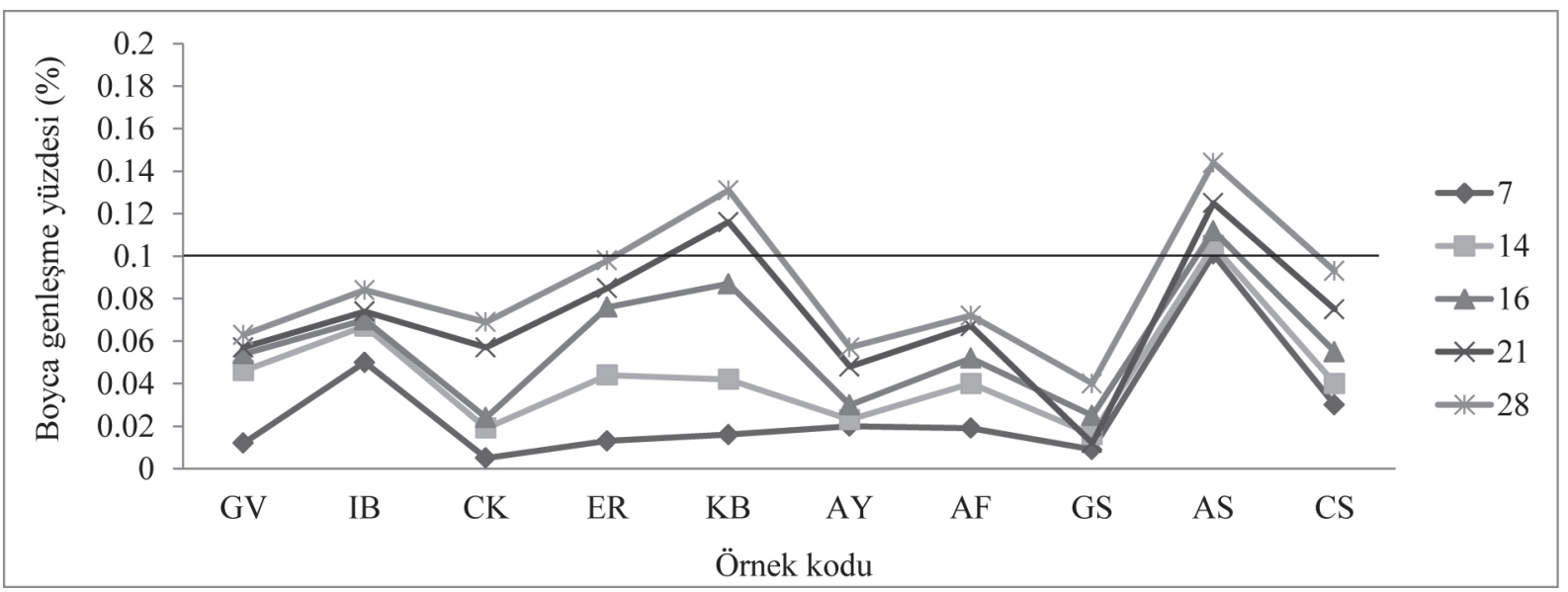

Şekil 4. 7, 14, 16, 21 ve 28 günlük genleşme değerlerinin değişimi.

Figure 4. Changes in expansion values at 7, 14, 16, 21 and 28 days.

\section{Taramalı Elektron Mikroskobu (SEM) İncelemeleri}

Hızlandırılmış harç çubuğu deneylerinde kullanılan örnekler üzerindeki alkali-silis reaksiyonu etkilerini gözlemlemek amaciyla
Taramalı Elektron Mikroskobu (SEM) incelemeleri yapılmıştır. Harç numunelerine ait elektron mikroskobu görüntüleri Şekil 5, 6, 7, 8, $9,10,11,12,13$ ve 14 'te sunulmuştur.
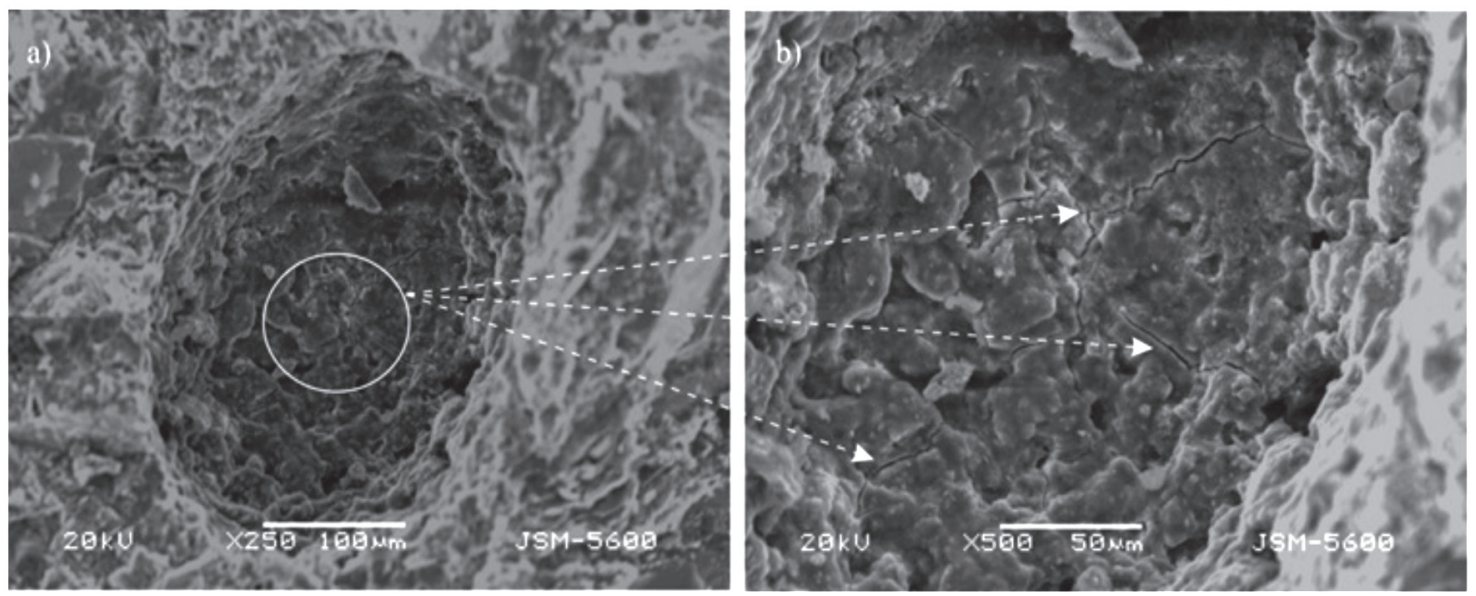

Şekil 5. GV kodlu granitlerden üretilen harç çubuklarının SEM görümleri: a) tane yüzeyinde gelişen tipik genleşme çatlakları, b) aynı çatlakların yakından görünümü.

Figure 5. SEM images of mortar bars produced by GV coded granite: a) typical expansion cracks developed on the particle surface, b) close view of same cracks. 

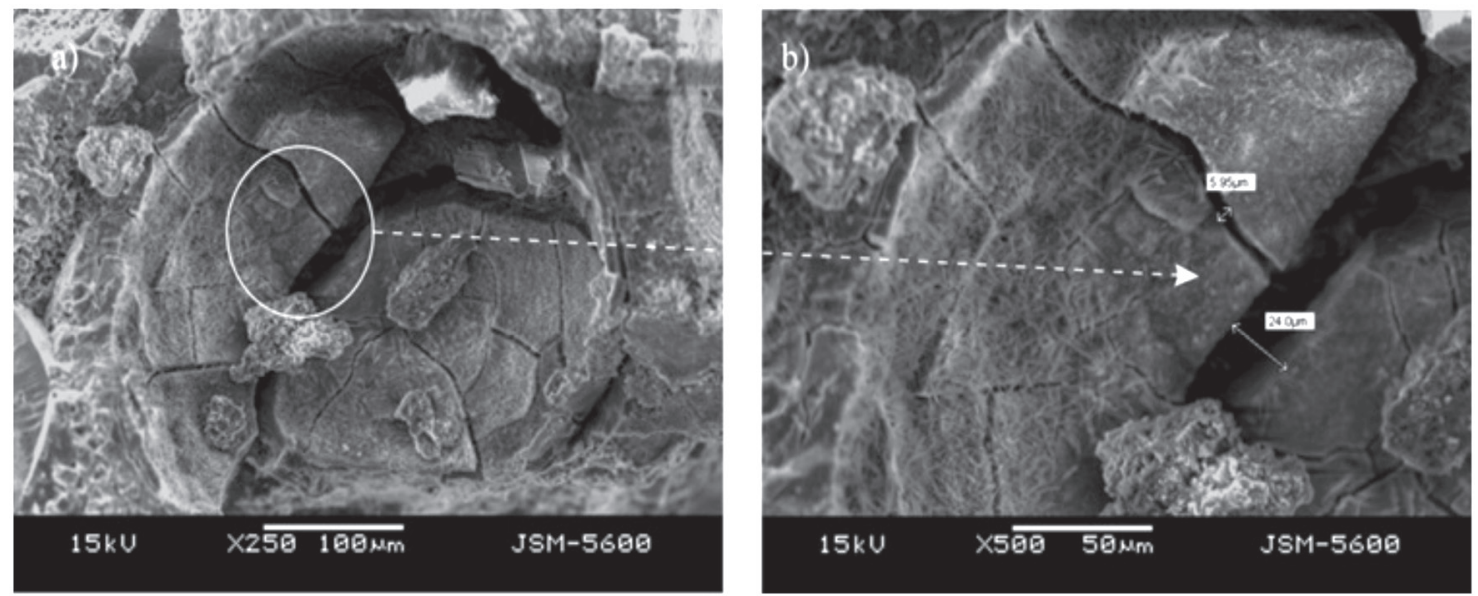

Şekil 6. IB kodlu granitlerden üretilen harç çubuklarının SEM görümleri: a) jelde oluşan genleşme çatlakları, b) aynı çatlakların ve çatlak açıklığının yakından görünümü.

Figure 6. SEM images of mortar bars produced by IB coded granite: a) expansion cracks developed in gel, b) close view of same cracks and crack aperture.
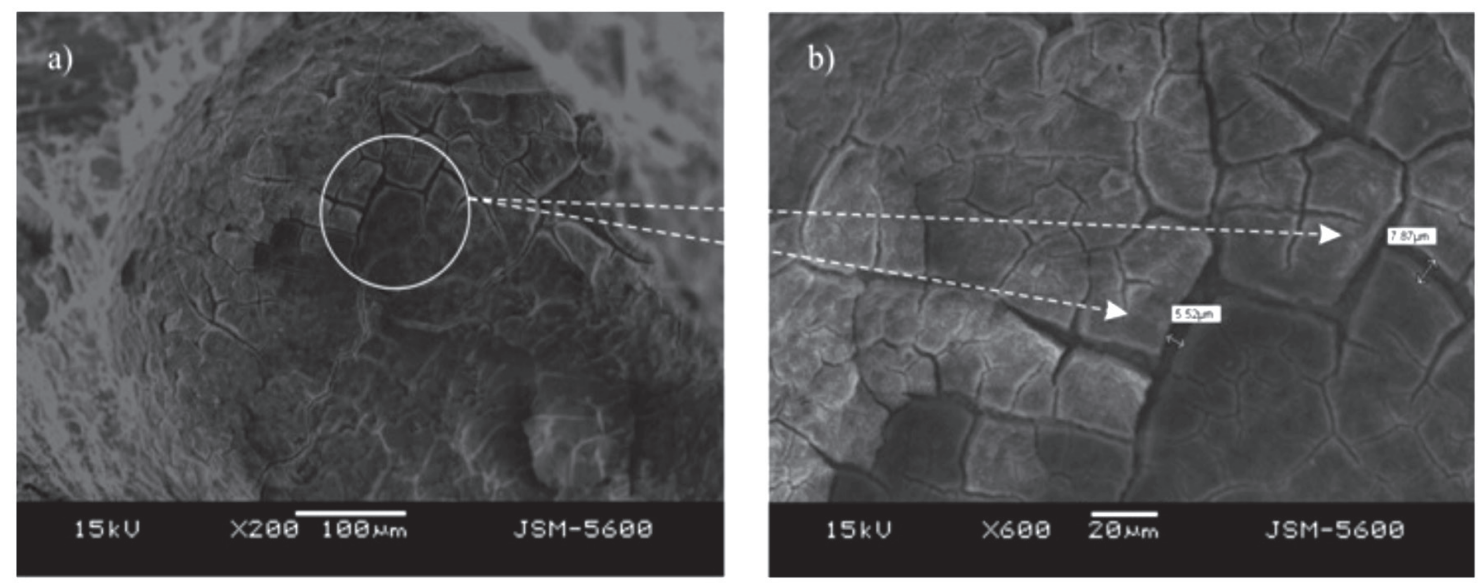

Şekil 7. CK kodlu granitlerden üretilen harç çubuklarının SEM görümleri: a) çatlakların görünümü, b) çatlakların yakından görünümü ve açıklık ölçümü.

Figure 7. SEM images of mortar bars produced by CK coded granite: a) view of cracks, b) close view of same cracks and crack aperture. 
Mannasoğlu, Yılmaz, Tuğrul
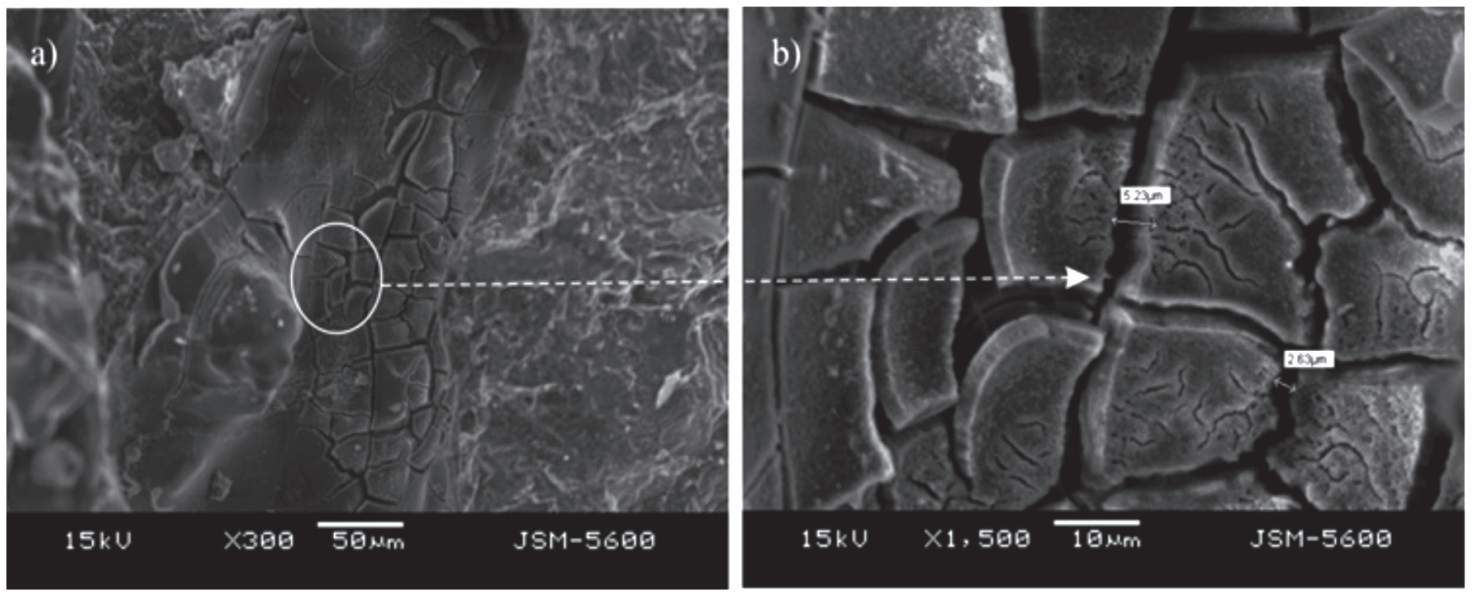

Şekil 8. ER kodlu granitlerden üretilen harç çubuklarının SEM görümleri: a) çatlakların görünümü, b) çatlakların yakından görünümü ve açıklık ölçümü.

Figure 8. SEM images of mortar bars produced by ER coded granite: a) view of cracks, b) close view of same cracks and crack aperture.
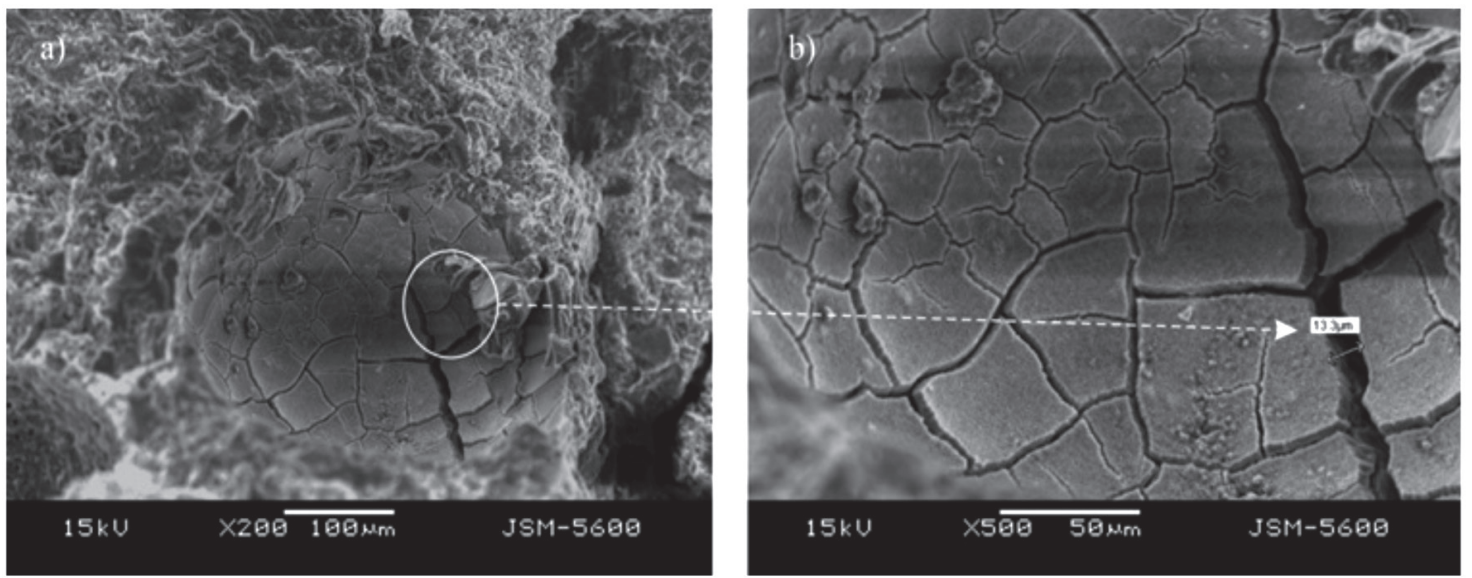

Şekil 9. KB kodlu granitlerden üretilen harç çubuklarının SEM görümleri: a) jelde oluşan tipik genleşme çatlakları, b) çatlak açıklığının yakından görünümü.

Figure 9. SEM images of mortar bars produced by KB coded granite: a) typical expansion cracks developed in gel, b) close view of crack aperture. 

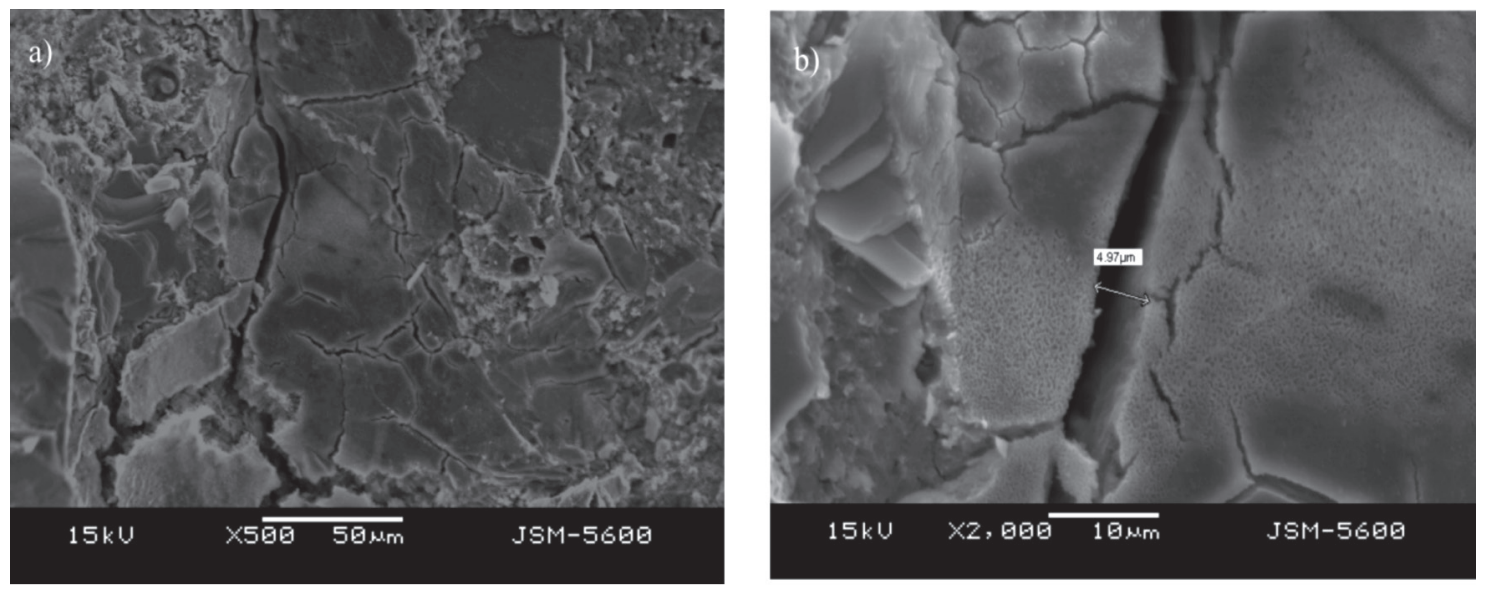

Şekil 10. a) AY kodlu granitlerden üretilen harç çubuklarının SEM görümleri, b) jelde oluşan tipik genleşme çatlakları. Figure 10. a) SEM images of mortar bars produced by AY coded granite, b) typical expansion cracks developed in gel.
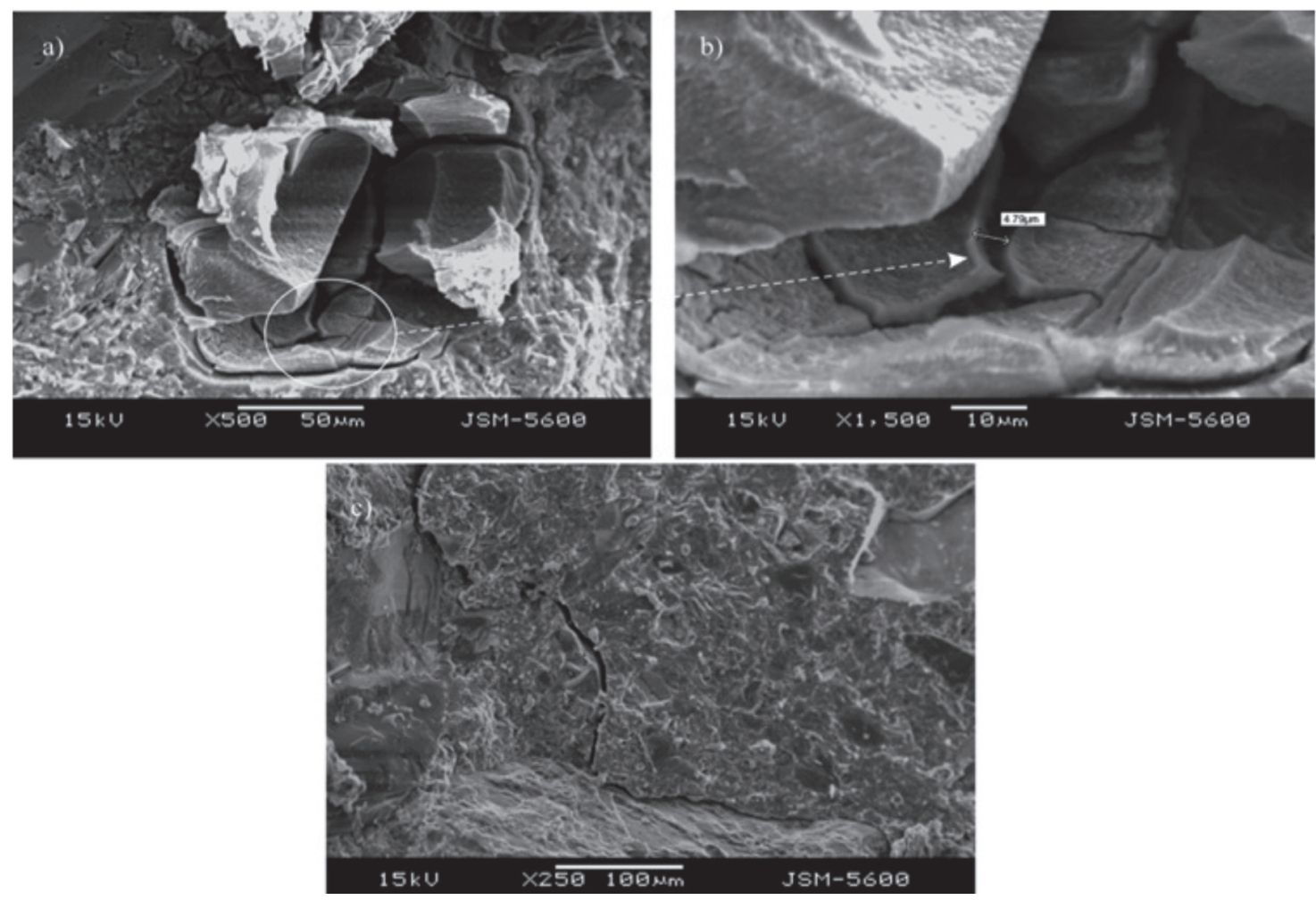

Şekil 11. AF kodlu granitlerden üretilen harç çubuklarının SEM görümleri ve jelde oluşan tipik genleşme çatlakları. Figure 11. SEM images of mortar bars produced by AF coded granite and typical expansion cracks developed in gel. 
Mannasoğlu, Yılmaz, Tuğrul
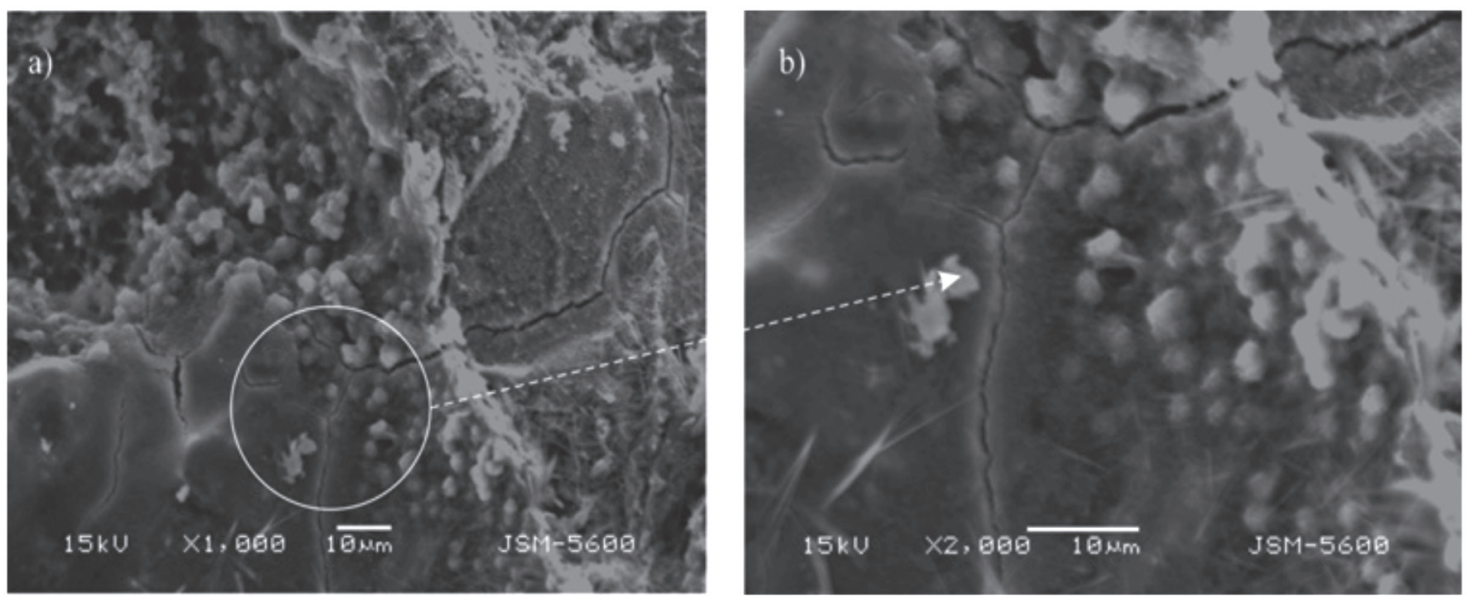

Şekil 12. GS kodlu granitlerden üretilen harç çubuklarının SEM görümleri: a) tipik genleşme çatlakları, b) aynı çatlakların yakından görünümü.

Figure 12. SEM images of mortar bars produced by GS coded granite: a) typical expansion cracks, b) close view of same cracks.
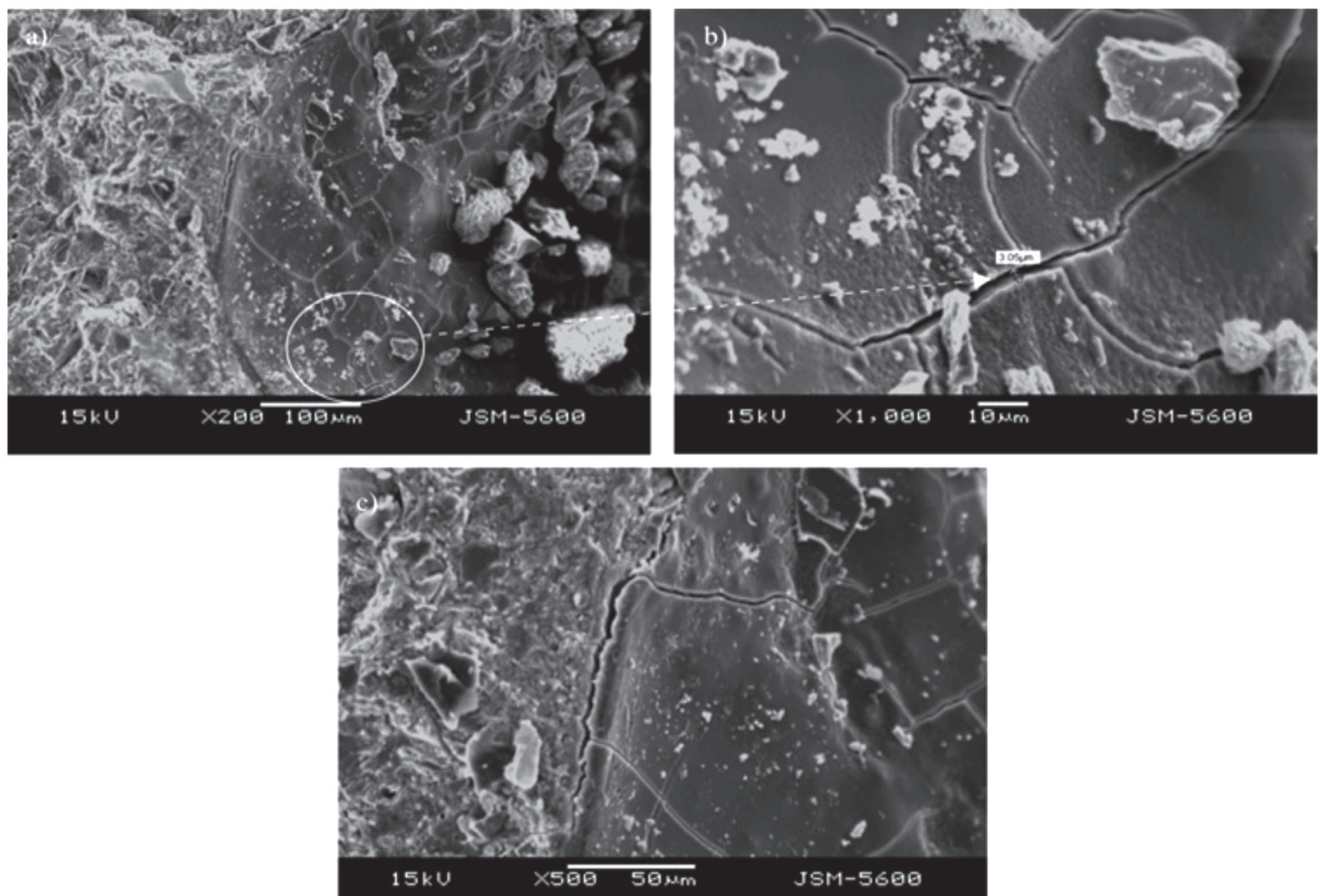

Şekil 13. a, b, c) AS kodlu granitlerden üretilen harç çubuklarının SEM görümleri: a, c) tipik genleşme çatlakları, b) aynı çatlakların yakından görünümü.

Figure 13. $a, b, c)$ SEM images of mortar bars produced by AS coded granite: a,c) typical expansion cracks produced in gel, b) close view of same cracks. 

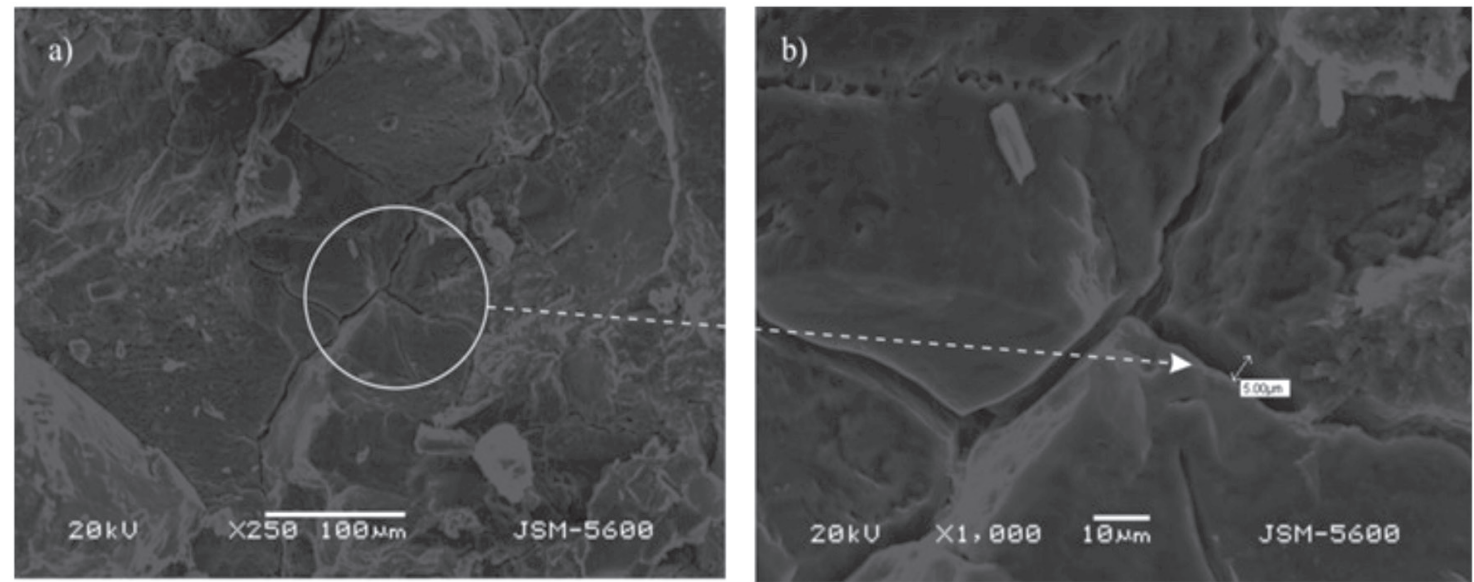

Şekil 14. CS kodlu granitlerden üretilen harç çubuklarının SEM görümleri: a) tipik genleşme çatlakları, b) aynı çatlakların yakından görünümü.

Figure 14. SEM images of mortar bars produced by AS coded granite: a) typical expansion cracks produced in gel, b) close view of same cracks.

\section{DENEYSEL VERILERIN DEĞERLENDİRILIMESİ}

Petrografik incelemelere göre; bu çalışmada kullanılan granitik kayaçlarda kuvars, ortoklaz, plajiyoklaz, hornblend ve biyotit ana mineraller olarak gözlenmiştir. Bunun yanı sıra; klorit, epidot, muskovit, serizit, kalsit ikincil mineral olarak, titanit, zirkon, apatit ve opak mineraller ise tâli mineraller olarak bulunmuştur. $\mathrm{Bu}$ minerallerden ikincil olanlar, ayrışma ve/veya hidrotermal alterasyon ürünleridir (Çizelge 1, 2 ve Şekil 2).

ASTM C 1260 (1994)'te, 16 günlük genleşme oranına göre değerlendirme yapılması gerektiği belirtilmiştir. Buna göre, genleşme oranı, \% 0.1'den düşük ise agrega "zararsı", $\% 0.2$ 'den büyük ise "potansiyel zararll" kabul edilmektedir. Genleşme oran1 \% 0.1-0.2 arasında ise ek bilgi sağlayan yöntemlere başvurulmalıdır. $\mathrm{Bu}$ yöntemler petrografik analiz ve alkali-silis reaksiyon ürünlerinin tanımlanmasıdır. Ayrıca, genleşme oranındaki değişime bağlı olarak deney süresi 21 ile 28 gün arasında değişebilir. Çizelge 5 'te görüldüğü gibi, hazırlanan harç çubuklarının 7 günlük boyca uzama yüzdesi ölçümleri sonucunda, ortalama en yüksek genleşmenin AS kodlu granitler ile hazırlanan harç çubuklarında, ortalama en düşük genleşmenin ise CK kodlu granitler ile hazırlanan harç çubuklarında olduğu belirlenmiştir. 16 günlük boyca uzama yüzdesi ölçümlerine bakıldığında, en yüksek boyca genleşme yüzdesinin AS kodlu örneğe ait olduğu, en düşük genleşme oranının ise CK kodlu örneğe ait olduğu belirlenmiştir. 16 gün sonunda elde edilen veriler sonucunda AS kodlu granitin genleşme oranının yukarıda belirtildiği gibi \% 0.1 'lik genleşme oranı limitini geçmesi, bu örneğin alkali silis reaksiyonu için potansiyel zararlı olduğunu göstermiştir. $\mathrm{Bu}$ sebeple Çizelge 5'te görüldüğü gibi deneyler 28 güne kadar uzatılmış ve sonuçta ortalama en yüksek genleşmenin yine AS kodlu granitler ile hazırlanan harç çubuklarında olduğu tespit edilmiştir (Şekil 4). 
Mannasoğlu, Yılmaz, Tuğrul

Çizelge 5. Granit örnekleriyle hazırlanan harç çubuklarının boyca genleşme yüzdeleri.

Table 5. Expansion percentages of mortar bars prepared with the granite samples.

\begin{tabular}{|c|c|c|c|c|c|c|}
\hline Örnek kodu & & 7. gün & 14. gün & 16. gün & 21. gün & 28. gün \\
\hline \multirow{3}{*}{ GV } & En Düşük & 0.007 & 0.021 & 0.025 & 0.026 & 0.030 \\
\hline & En Yüksek & 0.021 & 0.070 & 0.081 & 0.086 & 0.090 \\
\hline & $\%$ Ort. & 0.012 & 0.046 & 0.054 & 0.057 & 0.063 \\
\hline \multirow{3}{*}{ IB } & En Düşük & 0.012 & 0.018 & 0.021 & 0.024 & 0.028 \\
\hline & En Yüksek & 0.058 & 0.098 & 0.105 & 0.108 & 0.108 \\
\hline & $\%$ Ort. & 0.050 & 0.067 & 0.070 & 0.074 & 0.084 \\
\hline \multirow{3}{*}{$\mathrm{CK}$} & En Düşük & 0.001 & 0.007 & 0.008 & 0.036 & 0.044 \\
\hline & En Yüksek & 0.013 & 0.027 & 0.036 & 0.069 & 0.083 \\
\hline & $\%$ Ort. & 0.005 & 0.019 & 0.024 & 0.057 & 0.069 \\
\hline \multirow{3}{*}{ ER } & En Düşük & 0.007 & 0.023 & 0.072 & 0.074 & 0.084 \\
\hline & En Yüksek & 0.019 & 0.068 & 0.085 & 0.123 & 0.129 \\
\hline & $\%$ Ort. & 0.013 & 0.044 & 0.076 & 0.085 & 0.098 \\
\hline \multirow{3}{*}{ KB } & En Düşük & 0.004 & 0.007 & 0.066 & 0.081 & 0.095 \\
\hline & En Yüksek & 0.035 & 0.069 & 0.118 & 0.139 & 0.150 \\
\hline & $\%$ Ort. & 0.016 & 0.042 & 0.087 & 0.116 & 0.131 \\
\hline \multirow{3}{*}{ AY } & En Düşük & 0.004 & 0.006 & 0.010 & 0.018 & 0.026 \\
\hline & En Yüksek & 0.036 & 0.043 & 0.046 & 0.082 & 0.094 \\
\hline & $\%$ Ort. & 0.020 & 0.023 & 0.030 & 0.048 & 0.057 \\
\hline \multirow{3}{*}{$\mathrm{AF}$} & En Düşük & 0.010 & 0.014 & 0.021 & 0.022 & 0.023 \\
\hline & En Yüksek & 0.035 & 0.053 & 0.068 & 0.099 & 0.101 \\
\hline & $\%$ Ort. & 0.019 & 0.040 & 0.052 & 0.067 & 0.072 \\
\hline \multirow{3}{*}{ GS } & En Düşük & 0.002 & 0.009 & 0.009 & 0.002 & 0.021 \\
\hline & En Yüksek & 0.017 & 0.022 & 0.053 & 0.057 & 0.072 \\
\hline & $\%$ Ort. & 0.009 & 0.016 & 0.025 & 0.012 & 0.040 \\
\hline \multirow{3}{*}{ AS } & En Düşük & 0.098 & 0.103 & 0.109 & 0.115 & 0.123 \\
\hline & En Yüksek & 0.103 & 0.108 & 0.115 & 0.143 & 0.167 \\
\hline & $\%$ Ort. & 0.101 & 0.105 & 0.112 & 0.125 & 0.144 \\
\hline \multirow{3}{*}{$\mathrm{CS}$} & En Düşük & 0.016 & 0.022 & 0.031 & 0.047 & 0.069 \\
\hline & En Yüksek & 0.057 & 0.060 & 0.072 & 0.102 & 0.114 \\
\hline & $\%$ Ort. & 0.030 & 0.040 & 0.055 & 0.075 & 0.093 \\
\hline
\end{tabular}

Alkali silis reaksiyonunun etkilerini belirlemede kullanilan ve benzer deney yöntemlerinde biri olan CSA A23.2 (1994)'te ise 14 günlük genleşme oranları dikkate alınmaktadır. $\mathrm{Bu}$ standarda göre; 14 günlük genleşmelerin $\% 0.1$ 'den fazla olması durumunda agregalar reaksiyon açısından sakıncalı olarak değerlendirilmektedir. Özellikleri Çizelge 4'te sunulan çimento ile yapılan harç çubuklarının 14 günlük ortalama genleşme yüzdelerine bakıldığında, AS kodlu granitin yüzdesi standart limitin üzerindedir (Çizelge 5). 
İncelenen harç örneklerinden AS örneği dışındaki diğer tüm harç çubuklarında, 16 gün sonunda, alkali silis reaksiyonu oluşumu görülmemektedir (Çizelge 5). Bununla birlikte, granitlerin bileşiminde bulunan kuvars yüzdelerinin genleşme ile ilişkisini belirlemek amacı ile kuvars yüzdesi-genleşme diyagramları hazırlanmıştır (Şekil 15). 16 günlük genleşme diyagaramı incelendiğinde (Şekil 15a); AS kodlu örnek zararlı bölgede, KB, ER ve IB kodlu örnekler ise zararsız bölgede olup zararlı bölgeye en yakın yerde konumlanmışlardır. 21 günlük genleşme diyagaramı incelendiğinde (Şekil 15b);
KB kodlu örnekte genleşme oranı artmış ve AS kodlu örneğe yakın bir sonuç vermiştir. ER ve IB kodlu örneklerde fazla genleşme olmazken, CS kodlu örnekte genleşme artmıştır. 28 günlük genleşme diyagaramı incelendiğinde ise (Şekil 15c); AS ve KB'nin genleşmeleri artmaya devam etmiştir. ER, IB ve CS kodlu örneklerde az oranda genleşme devam etmiştir. Başta AS olmak üzere KB kodlu örnekte de görülen yüksek genleşmenin, bu örneklerin bileşiminde bulunan ve metamorfizmadan etkilenen kuvarslardan kaynaklandığı düşünülmektedir.

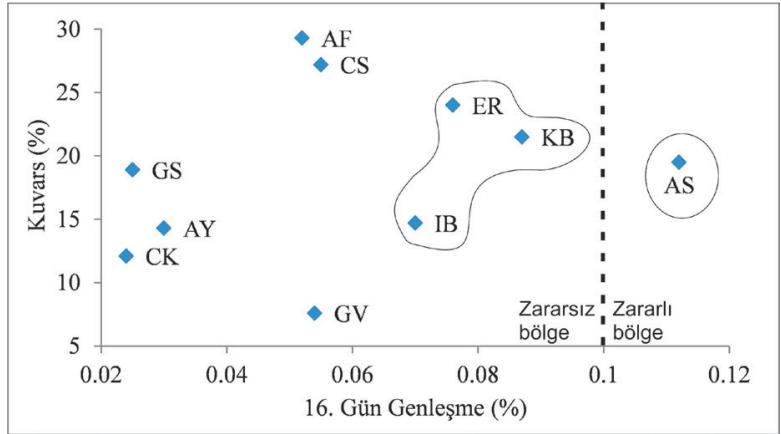

(a)

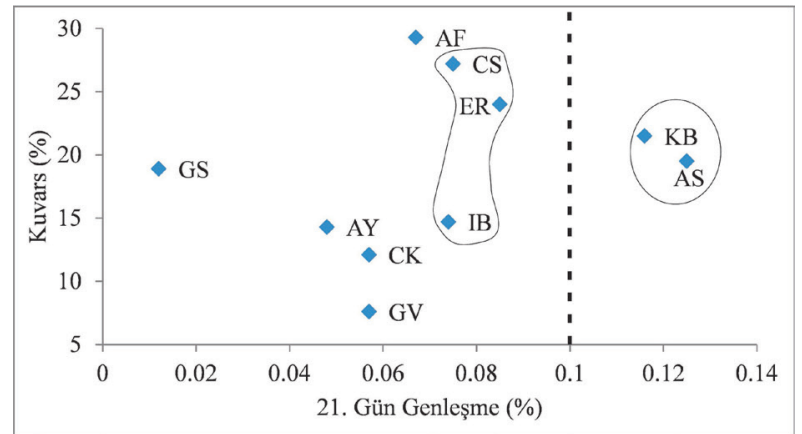

(b)

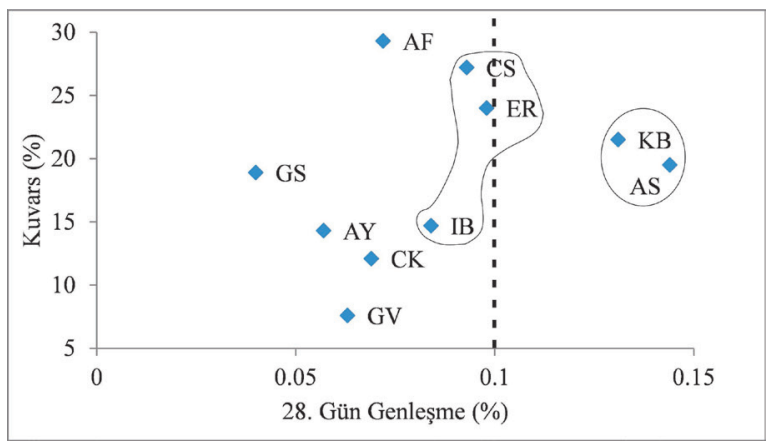

(c)

Şekil 15. Granitler içerisindeki a) 16 günlük b) 21 günlük c) 28 günlük kuvars yüzdesi genleşme diyagramları.

Figue 15. a) 16 day b) 21 day c) 28 day expansion diagrams including quartz percentage in the granties. 
Mannasoğlu, Yılmaz, Tuğrul

Alkali silis reaksiyonunun meydana gelmesi ile ilgili pek çok çalışma yapılmıştır. Ben Haha (2006) tarafindan da belirtildiği gibi, yeni yapılmış betonda reaksiyon oluşmasını engellemek amacı ile yeni metodlar geliştirilmesine rağmen, gelecekte meydana gelebilecek reaksiyon ve etkileri belirlemek için de bazı çalışmalar yapılması gerekmektedir. Alkali silis reaksiyonu, kompleks mineral yapısı olan ve reaktif olmayan agregalarda son derece yavaş ilerleyen bir olaydır. Bu sebeple reaksiyon aşamalarını tespit etmek için; agregadaki mevcut reaktivite derecelerini, mevcut durum ve gelecekteki reaksiyon potansiyelini, mekanik özelliklerini ve betondaki boyutsal genleşmeyi gözlemlemek gerekir (Ben Haha, 2006). Bu amaç ile harç çubuklarından elde edilen numuneler üzerinde taramalı elektron mikroskobu (SEM) incelemeleri yapılmıştır.

Granitler üzerinde yapılan petrografik incelemelerde her ne kadar alkali silis reaksiyonuna neden olabilecek kuvars polimorflarına rastlanmasa da, Stanton (1940), Gogte (1973), Shrimer vd. (2000) ve Bell (1998) tarafindan da belirtildiği gibi, metamorfizma etkisi ile kuvarsların basınç altında kalması ve çatlaklı olması alkali silis reaksiyonuna neden olabilmektedir. $\mathrm{Bu}$ nedenle yapılan SEM incelemeleri sonucunda, numunelerde çatlaklara rastlanmıştır. Granit tanelerinin yüzeyinde ince bir kabuk oluştuğu ancak bu kabukta çatlakların gelişemediği ya da çok az geliştiği görülmüştür. $\mathrm{Bu}$ çatlaklar fazla olmamakla birlikte agrega yüzeyini kaplayan jelde meydana gelmiş olup, katılaşmış harcın bütün alanında gözlemlenmemiştir.

Deneylerde kullanılan harç çubuklarından elde edilen SEM görüntülerinde, incelenen granitik kayaçlar ile üretilen harç çubuklarının alkali silis reaksiyonundan az miktarda etkilendikleri görülmektedir. Jeller tanelerin üzerini kaplamış ve çatlaklara neden olmuştur. Ancak jel oluşumu fazla olmadığı için ve dolayısıyla genleşme de fazla gerçekleşmediği için meydana gelen bu açıklıklar oldukça küçük miktardadır. SEM görüntüleri incelendiğinde oluşan jel sebebi ile meydana gelen çatlakların genellikle çizgisel, dairesel ve ağ şeklinde bir yap1 gösterdiği görülmektedir (Şekil 5, 6, 7, 8, 9, $10,11,12,13$ ve 14$)$.

Reaktif agrega tanelerinin boyutları, alkali silis reaksiyonu sonucunda harç çubuklarında belirlenen ve geniş bir yayılım sergileyen genleşmeye büyük oranda etki ederler (Diamond ve Thaulow, 1974; Lu vd., 2006). Nitekim incelenen granitik kayaçlardan ince taneli olanlar (ER), orta-iri taneli olanlardan (KB, AY, AF, GS) daha az genleşmeye neden olmuşlardır.

\section{SONUÇLAR}

Çalışmaya konu olan granitik kayaçlar monzonit, granit ve granodiyorit bileşimlerinde olup, bunlardan bazıları metamorfizmaya, bazıları da az oranda yüzeysel ayrışma ve/veya hidrotermal alterasyona uğramışlardır.

Granitik kayaçlar kullanılarak hazırlanan harç çubukları üzerinde yapılan hızlandırılmış harç çubuğu deney sonuçlarına göre; örneklerin çoğunluğu standartlarda verilen limit değerlerin altında kalırken, metamorfizmaya ugramış granit/ monzogranit örneklerinde genleşme değerleri bu limitlerin üzerine çıkmıştır.

Granitik kayaç örnekleri ile hazırlanan harç çubuklarındaki genleşme oranı sınırlı olduğundan yapılan SEM incelemelerinde reaksiyon sonucu 
gelişen jelin ve bu jeldeki genleşme çatlaklarının sinırlı olduğu, özellikle boşluklarda geliştiği görülmüştür. Ayrıca bu incelemelerde genleşme çatlaklarının sadece agrega yüzeyini kaplayan jelde meydana geldiği görülmüştür.

Her ne kadar ASTM C1260'da 16 günlük genleşme oranı dikkate alınsa da; yapılan değerlendirmelerde; farklı granit örnekleri ile hazırlanan harç çubuklarındaki alkali-silis ve alkali-silikat reaksiyonu etkilerini belirlemek için hızlandırılmış harç çubuğu deneylerinin en az 21 gün devam ettirilmesinin, daha doğru sonuç almak için gerekli olduğu sonucuna varılmıştır.

\section{KAYNAKLAR}

Arnould, M., 1997. Alkali reaction with silico alkaline aggregates results of recent researches in France. Proceedings'97 International Three Gorges Project Technical Seminar, Yichang, China, 184195.

ASTM C 1260, 1994. Standard method for potential alkali-silica reactivity of aggregates (mortar bar method). Annual Book of ASTM Standards, Volume 04.02, Concrete and Aggregates, 648651.

ASTM C 289, 1994. Potential alkali-silica reactivity of aggregates (chemical method). Annual Book of ASTM Standards, Volume 04.02, Concrete and Aggregates, 157-163.

ASTM C 295, 1994. Petrographic Examination of Aggregates for Concrete. Annual Book of ASTM Standards, Volume 04.02, Concrete and Aggregates, 1-8.

Bell, F.G, 1998. Engineering Geology. Blackwell Science, Oxford, $579 \mathrm{p}$.

Ben Haha, M., 2006. Mechanical effects of alkali silica reaction in concrete studied by sem- image analysis. Swiss Institute of Technology Lausanne, These No. 3516.

Binal, A., 2008. The determination of gel swelling pressure of reactive aggregates by ASGPM devices and a new reactive-innocuous aggregate decision chart. Construction and Building Materials, 22, 1-13.

BS 812 Part 123, 1999. Method for the determination of alkali - silica reactivity: Concrete prism method. British Standards Institution, $18 \mathrm{p}$.

BS 7943, 1999. Guide to the interpretation of petrographical examinations for alkali-silica reactivity. British Standards Institution, 20 p.

Buck, A.D., 1986. Petrographic criteria for recognition of alkali-reactive strained quartz, evaluation of quartzite and granite aggregates containing strained quartz. Proceedings of the 7 th International Conference on Alkali-Aggregate Reaction, Ottawa, 419-423.

CSA (Canadian Standards Association), 1994. Test method for detection of alkali-silica reactive aggregate by accelerated expansion of mortar bars. A23.2-25A, Methods of Test for Concrete, Canadian Standards Association, Ontario, Canada, 236-242.

Diamond, S., and Thaulow, N., 1974. A study of expansion due to alkali-silica reaction as conditioned by the grain size of the reactive aggregate. Cement and Concrete Research, 4, 591-607.

Erkan, Y., 2004. Magmatik Petrografi, TMMOB Jeoloji Mühendisleri Odası Yayınları, 93, Ankara, 176 s.

Fookes, P.G., 1980. An introduction to the influence of natural aggregates on the performance and durability of concrete. Quarterly Journal of Engineering Geology, 123, 207-229. 
Mannasoğlu, Yılmaz, Tuğrul

Fournier, B., and Berube, M.A., 2000. Alkaliaggregate reaction in concrete: a review of basic concepts and engineering implications. Canadian Journal of Civil Engineering, 27, 167-191.

Gillott, J.E., and Rogers, C.A., 1994. Alkali-aggregate reaction and internal release of alkalis. Magazine of Concrete Research, 167, 99-112.

Gogte, B.S., 1973. An evaluation of some common Indian rocks with special reference to alkaliaggregate reactions. Engineering Geology, 7, $135-153$.

Hobbs D.W., and Gutteridge, W.A., 1979. Particle size of aggregate and its influence upon the expansion caused by the alkali-silica reaction. Magazine of Concrete Research, 31, 235-242.

Hornibrook, F.B., Insley, H., and Schuman, L., 1943. Report on committee C-1 on cement (appendix). Proceedings American Society Test Materials 43, $218 \mathrm{p}$.

Ineson, P.R., 1990. Siliceous components in aggregates. Cement and Concrete Composites, $12,185-190$.

Joyce, A.S., 1996. Petrographic aspects of alkalisilica reaction in Eastern Australian concretes. Proceedings of the 10th International Conference on Alkali-Aggregate Reaction in Concrete, Melbourne, 767-774.

Katayama, T., and Kaneshige, Y., 1986. Diagenetic changes in potential alkali-aggregate reactivity of volcanic rocks in Japan-A geological interpretation. Proceedings of the 7th International Conference on Alkali-Aggregate Reaction, P.E., Grattan-Bellew (ed.), Ottawa, Canada, 489-493.

Landgren, R., and Sweet, S., 1952. Investigation of durability of Wyoming aggregates. Proceedings Highway Restoration Board, 31, 202-217.

Lorenzi, G., Jensen, J., Wigum, B., Sibbick, R., Haugen, M., Guédon, S., and Åkesson, U.,
2001. Petrographic atlas of the potentially alkalireactive rocks in Europe. PARTNER-projectGRD1-CT-2001-40103.

Lu, D., Fournier, B., and Grattan-Bellew, P.E., 2006. Evaluation of accelerated test methods for determining alkali-silica reactivity of concrete aggregates. Cement and Concrete Composites, $28,546-554$.

Marzouk, H., and Langdon, S., 2003. The effect of alkali-aggregate reactivity on the mechanical properties of high and normal strength concrete. Cement and Concrete Composites, 25, 549-556.

McConnell, D., Mielenz, R. C., Holland, W.Y., and Grene, K.T., 1950. Petrology of concrete affected by cement aggregate reaction. In Application of Geology to Engineering Practice, S. Paige (ed.), Berkey Volume, Memoir American Geological Society, 222-250.

Mielenz, R.C., 1954. Petrographic examination of concrete aggregate. Proceedings American Society Test Materials, 54, 1188-1218.

Moranville-Regourd, M., 1997. Modelling of expansion induced by ASR-new approaches. Cement and Concrete Research, 19, 415-425.

Mullick, A.K., Wason, R.C., Sinha, S.K., and Rao, L.H., 1986. Evaluation of quartzite and granite aggregates containing strained quartz. Proceedings of the 7th International Conference on Alkali-Aggregate Reaction in Concrete, Ottawa, 428-433.

Neville, A. M., 1981. Properties of Concrete. Longman Scientific \& Technical, London, England.

Nixon, P.J., and Page, C.L., 1987. Pore solution chemistry and alkali aggregate reaction. American Concrete Institute Special Publication, 100, 1833-1862.

Prince, W., Castanier, G., and Giafferi, J.L., 2001. Similarity between alkali-aggregate reaction 
and the natural alteration of rocks. Cement and Concrete Research, 31, 271-276.

Rivard, P., Ollivier, J.P., and Ballivy, G., 2002. Characterization of the ASR rim application to the Potsdam sandstone. Cement and Concrete Research, 32, 1-9.

Rhoades, R., 1942. Discussion of a paper by Stanton, Porter, Meder and Nicol: California experience with the expansion of concrete through reaction between cement and aggregate. Journal of American Concrete Institute Proceedings, 38, 7-11.

Shayan, A., and Lancucki, C.J., 1986. Alkaliaggregate reaction in the Causeway Brigde, Perth, Western Australia. Proceedings of the 7 th International Conference on Alkali-Aggregate Reaction in Concrete, Ottawa, 392-397.

Shrimer, F. H., Ooi, O., and Gerry, W. J., 2000. Control of alkali-aggregate reactivity, Pointe Seraphine Berth improvements, St. Lucia. 11th International Conference on Alkali-Aggregate Reaction, M.A. Bérubé, B. Fournier, B. Durand (eds.), Quebec, Canada, 473-482.

Stanton, T.E., 1940. Influence of cement and aggregate on concrete expansion. Engineering News Record, February 1, 59-61.
Stark, D., Morgan, B., Okamoto, P., and Diamon, S., 1993. Eliminating or minimizing alkali-silica reactivity. Strategic Highway Research Program, National Research Council Washington.

Streckeisen, A., 1967, Classification and Nomenclature of Igneous Rocks, Neues Jahrbuch Fur Mineralogie-Abhandlungen, 107, 144-240.

Struble, L.J., and Diamond S., 1981. Swelling properties of synthetic alkali-silica gel. Journal of the American Ceramic Society, 64(11), 61155.

Swamy, R.N., 1992. Alkali-aggregate reaction in concrete; material and structural implications, sciences in concrete technology. Energy, Mines and Resources, Ottawa Canada, 533-581.

TS 2517, 1977. Alkali agrega reaktivitesinin kimyasal yolla tayini. Türk Standartları Enstitüsü, Ankara, $8 \mathrm{~s}$.

Wakizaka, Y., 1998. Reactivity of rocks and minerals in alkaline solution. Journal Research, Public Works Research Institutes, 34-146. 
